\title{
EFFECT OF DIFFERENT PARAMETERS ON THE FATIGUE CHARACTERISTICS OF FIBER REINFORCED POLYMER COMPOSITES-A REVIEW
}

\section{SANTOSH SAVNUR, VINAYAK UPPIN \& I. SRIDHAR}

Department of Mechanical Engineering, KLS VDIT, Haliyal, Karnataka, India

Department of Mechanical Engineering, JCE Belagavi, Karnataka, India

Department of Mechanical Engineering, SDMCET, Dharwad, India

\begin{abstract}
Composite materials are used extensively in diversity of applications ranging from aerospace, marine, infrastructure application to sport equipment. During their service life, these materials are subjected to fatigue loading. This review was initiated to collect and recognize literature dissemination by emphasizing the value of understanding the fatigue characteristics of FRP with changing environmental conditions (Moisture, Temperature) and with the involvement of different nano- fillers, composite tubes, fiber volume fractions. Due to their reactions against fatigue loading and constituents like fibre, matrix and fiber / matrix interface in these environments, their reliability and integrity in different service environments can be changed. The characterics of the fatigue damage in the composite materials is more complex, where at the beginning stage of fatigue growth many micro cracks starts, these results in the beginning of numerous types of fatigue damage. This review paper examines the impacts of various parameters on the behavior of fatigue in various polymer composites reinforced by fibers.

KEYWORDS: Fatigue Characteristics, S-N Behavior, Hygrothermal
\end{abstract}

Received: Jun 06, 2020; Accepted: Jun 26, 2020; Published: Aug 24, 2020; Paper Id.: IJMPERDJUN2020867

\section{INTRODUCTION}

The higher demand for fiber-reinforced polymer composites in current years in the discipline of aerospace, marine, sports, and construction due to its strong physical strength and high rigidity. The effect of environmental aging on composites is significantly observed from ships to under water equipment used in marine structures, aging in the environment is a fundamental component in the multi-scale modeling of composite behavior, but it cannot be restricted to strong mechanical perspectives. It is a multidisciplinary issue where chemistry, polymer science, and interactions between fluid and structure all play a vital role [1]. Composite material properties depend on the type of fiber, matrix type, interface properties, structure, and geometry. Different kinds of reinforcing fibers like glass, carbon, aramid and natural fibers are available to develop the products with good properties compared to traditional materials. A blending of filler materials such as calcium carbonate, silica nanoparticles, clay, etc. leads to enhance structural properties [2-4].

There are various techniques used for preparing the laminated composites like hand-lay, vacuum bagging, filament winding, and pressure molding [5]. Fiber volume fraction plays a vital role in defining properties like stiffness, ultimate strength, and rigidity of the laminated composites [6]. Due to the inclusion of fillers in micro and nano scales which helps in substantial betterment in the mechanical properties [7-10]. Because of the resistance to corrosion and structural strength, the fiber-reinforced polymer tubes are gaining additional attentiveness in current oil and gas companies. The rapid growth in its usability of composite materials reaches nearly every engineering 
field. This is due to higher specific strength to their lower weight [11-12]. The characteristics of composite materials are corrosion sensitive because composite materials are subjected to a wide variety of environmental factors. The degradation of the materials may occur due to chemical alteration in the polymer content, fiber swelling, and moisture catching and debonding at the surface of the fiber matrix.

\section{MOISTURE}

Fiber-reinforced polymers are extensively used in cyclic environments like combination of moisture and temperature. Many researchers reported that the influence of the polymer matrices and their respective composites in the field of hygrothermal aging [13-14]. The influence of the short glass fiber content and the impact of water intake on fatigue nature was reported by Ayman MM Abdelhaleem [15]. In this study recycled polypropylene (RPP) was reinforced with distinct weight percentage of short glass fiber $(5 \mathrm{wt} \%, 10 \mathrm{wt} \%, 20 \mathrm{wt} \%, 30 \mathrm{wt} \%) \&$ was compared with pure polypropylene (PP). Resulting short glass fiber incorporated recycle polypropylene (RPP) absorbed more water compare to pure polypropylene. Increasing the short fiber content in recycling polypropylene (RPP) leads to an enhance in fatigue strength under both dry and wet circumstances refer to Figure $1 \& 2$.

E.poodts et.al. [16] developed the glass fiber reinforced composite using two resin systems i.e polyester and vinyl ester. In this case of fatigue study, the test was conducted before and after exposure to water, and tests under both wet and dry conditions. There was no noticeable divergence in the fatigue result by the aged samples with respect to the unprocessed samples. Fatigue response under two different resin systems as shown in Figures 3 and 4. However, the method of preparation of specimens and the nature of matrix do influence the kinetics of the water incorporation into these composites and the water diffusion state [19].

The experimental investigation into the effect of water aging on flexural fatigue behavior of unidirectional polypropylene (PP)-glass (G) fiber-reinforced epoxy composites was conducted by MA Abd El-Baky [17]. In both dry and wet sample conditions, the effect of reinforcement hybridization, hybrid configuration, i.e. interplay or intraply, and pile stacking series on fatigue behavior was studied. Water absorption was minimal for peripheral hybrid composites with glass fiber and core polypropylene fiber, GFRP samples showed that, the fatigue strength is 6.57 higher than that of PFRP specimens, as well as hybrid composite strength values (50\% pp: $50 \% \mathrm{G}$ ) depending on the hybrid pattern and stacking pattern. The influence of hydrothermal treatments on fatigue behavior was studied by Jones et.al. [18]. for carbon fiber/PEEK composite and carbon/ epoxy material for the same tailoring constraints. The cross-ply laminate was developed for both the configuration and examined in repeated tension for $0^{0}$ and $45^{0}$ to the fiber loading axis. In both the configurations, there was no influence of hygrothermal treatments. And also, $\pm 45^{\circ}$ orientationof cross-plied carbon/PEEK laminate showed better fatigue response as compare to the carbon/epoxy composites. The superior PEEK matrix characteristics cause for this better response. Tual et.al [19] carried research to determine the result of aging in seawater on the mechanical behavior of carbon/epoxy composites for under water turbine blades using the accelerated aging test for different material orientation and thickness to distinguish water diffusion behavior at different temperatures. The author concluded that the thickness and orientation of these materials have a small impact on the kinetics of water diffusion due to the diffusion of seawater in the composite material, but there were no drastic changes in the elastic modulus. Menail et.al [20] conducted research on the effects of aging due to water during fatigue cycles on the mechanical characteristics of epoxy composites reinforced by glass fibers and kevlar fibers. Samples were initially subjected to fatigue load for ' $\mathrm{n}$ ' number of cycles and aged for different lengths of time by immersion in tap water and in seawater after the composite samples were applied to tensile tests to find out the strength and rigidity of water absorption and 
fatigue during local interactions.

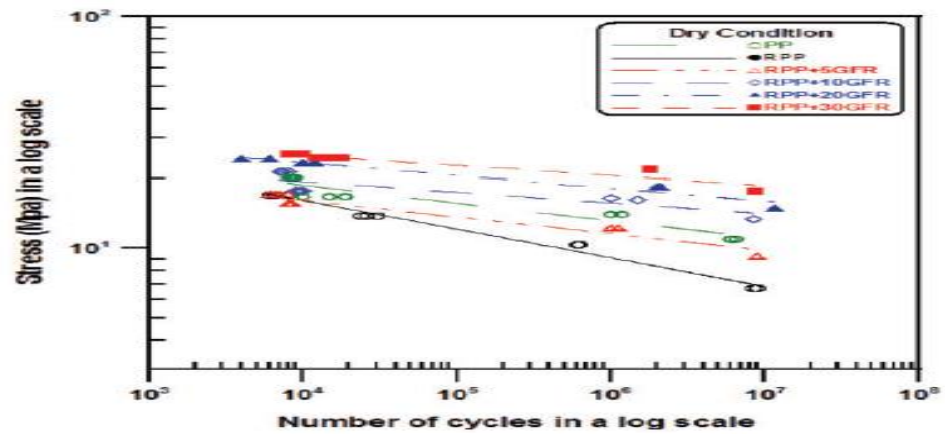

Figure 1: S-N Behavior Under Dry Condition.

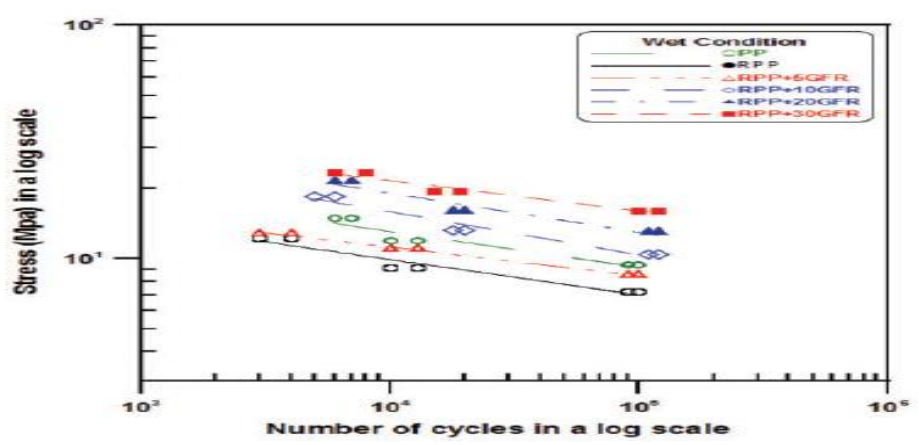

Figure 2: S-N Behavior Under Wet Condition.

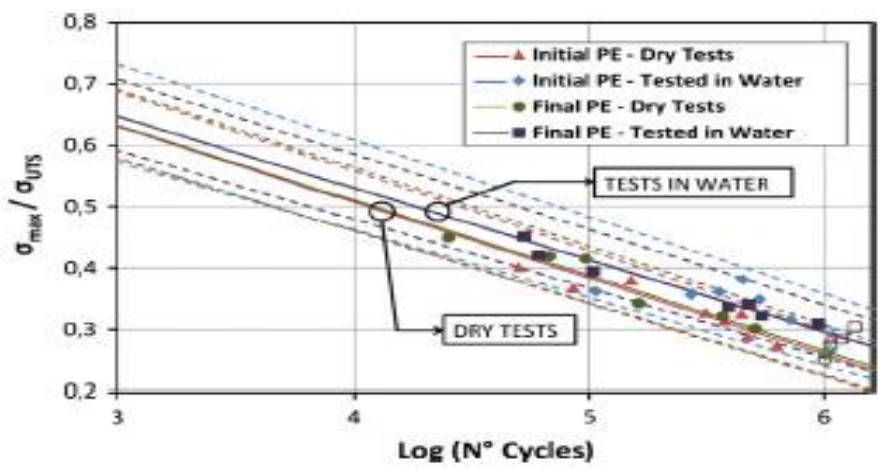

Figure 3. Fatigue Behavior of E-Glass Polyester Samples.

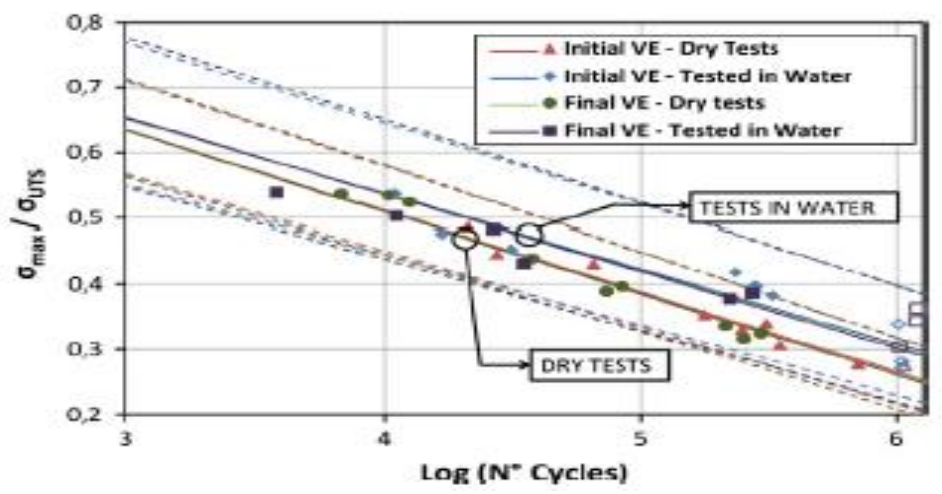

Figure 4. Fatigue Behavior of E-Glass Vinylester Samples.

\section{TEMPERATURE EFFECT}


The fiber-reinforced polymer matrix composites are exhibits viscoelastic behavior, and the working temperature influences their mechanical properties. Reduction of strength, modulus, and fatigue life was observed when the temperature rises to the glass transition (Tg). Carbon fiber composites with strong matrices are beneficial for low-temperature applications. Ahlborn et.al [21] reported on the fatigue nature of carbon fiber reinforced polymer composites with a $60 \%$ fiber volume fraction at $\mathrm{R}=0.1$. Table 1 shows the lay-up and structure of the five composites being examined, and fatigue experiments were also performed at three different temperatures. Uni-directional composites exhibited good fatigue behavior compared to multidirectional composites. Which was the influence of the proportion of fibers in the load direction and the cracks developed in transverse layers. The influence of temperature on fatigue performance was studied by vina et.al [22] for glass fiber reinforced polypropylene composite. Experimentation was carried at three different temperatures (ambient temperature, $60^{\circ} \mathrm{C}$, and $100^{\circ} \mathrm{C}$ ) at stress ratio 0.1 and frequency of $4 \mathrm{~Hz}$. Resulting a similar fatigue response was observed at ambient temperature, and at $60^{\circ} \mathrm{C}$ and a decrease in fatigue strength at $100^{\circ} \mathrm{C}$ by referring to figure 5 . The decrease in the response may be due to the viscoelastic behavior of the matrix.

Figure 5 showsJen et.al [23] examined fatigue behavior of two cross-ply and quasi-isotropic layers AS-4/PEEK laminated composite. The fatigue test was conducted for various temperatures ranging from $25^{\circ} \mathrm{C}$ to $150^{\circ} \mathrm{C}$ under the loading of tensiontension fatigue. The samples were exposed up to $10^{6}$ cycles of fatigue loading. For cross-ply laminates, the ultimate tensile test was higher than in quasi-isotropic laminates at different temperatures. In the fatigue life case, the slope of the standardized S-N diagram for quasi-isotropic composites is greater than the cross-ply composites at high temperature.

The predication of the damage through delamination strongly depends on determining the durability of the interlaminar fracture under static and fatigue load. Charalambous et al[24] investigated temperature effect on delamination growth under mixed-mode loading conditions. It was observed from the result that temperature can be related to the delay or enhance the effects on delamination growth applied to the loading system, i.e. either dynamic or static. The unstable crack propagation was noticed at a cold temperature under mode I with fatigue and static loading [25]. The fatigue strength reduction factor (FLRF) of glass fiber reinforced polyester composites at $60^{\circ} \mathrm{C}$ was $46 \%$ compared to the room temperature environment refer to figure 6. And also, the percentage of decrease in strength for fatigue was more than the percentage of decrease in tensile for all ranges of temperatures [26].

Table 1: List of the Tested CFRPs Components

\begin{tabular}{|c|l|c|c|}
\hline S. No & \multicolumn{1}{|c|}{ Layup } & Fiber type & Matrix \\
\hline 1 & UD & T300 & Rigid epoxy resin \\
\hline 2 & UD-Structural element & T300 & Rigid epoxy resin \\
\hline 3 & Cross ply $\left[0^{0} / 90^{\circ} / 0^{\circ} / 90^{0} / 0^{0}\right]$ & HTA7 & Thermoplastic polymer \\
\hline 4 & Quasiplanar $\left[0^{0} / \pm 45^{0} / 90^{0}\right]$ & T300 & Rigid epoxy resin \\
\hline 5 & Quasiplanar $\left[0^{0}, 90^{\circ} / \pm 45^{\circ}\right]$ structural element & HTA7 & Rigid epoxy resin \\
\hline
\end{tabular}




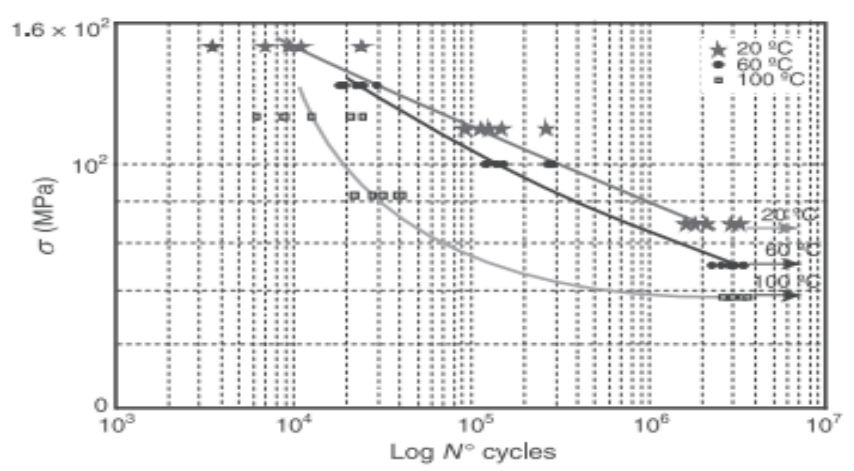

Figure 5: Temperature Effect on S-N Behavior.

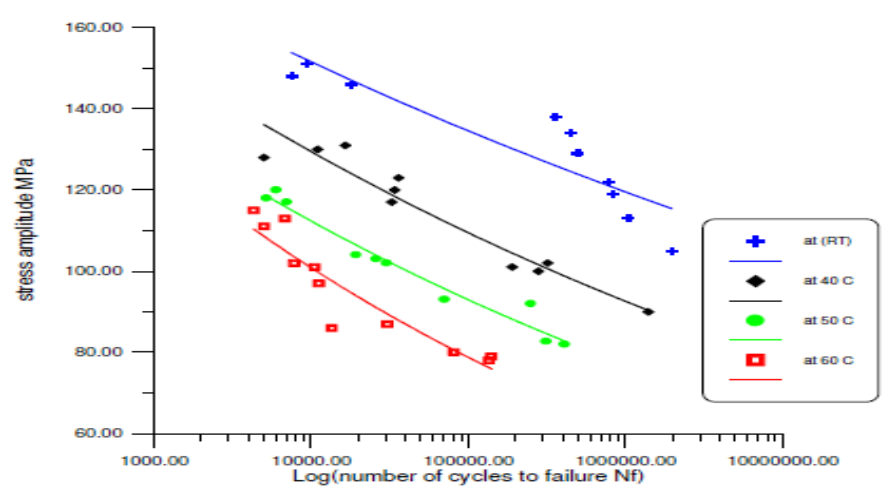

Figure 6: S-N Curve for [0/90]3 Laminate at Different Temperature [26].

\section{FILLER MATERIALS}

Extending the applications of the polymer composite is limited due to the sudden catastrophic failure, with a linear elastic response of failure. This nature of failure may be due to the brittle propertie of the matrix. One way to get better material behavior of fiber-reinforced polymers is by incorporating second-phase fillers to the resin to enhance the matrix properties. The ultimate failure of the laminated polymer composite is the function of the type of matrix used and the type of filler incorporated to develop the composite structures [27-28]. The change in the fatigue response also can be achieved by incorporating the nanofiller to the matrix [29-30-31]. Glass fiber reinforced polymer composite developed using silica nanoparticles shown improved fatigue life around three to four times as compared to without epoxy modified GFRP. The inclusion of the silica nanoparticles leads to a decline in the unstable crack propagation [32]. From Figure $7 \& 8$ it is also seen that GFRP composites with various matrices over the total series of stress level examined, the inclusion of 9wt \% CTBN rubber micro particles (NRR) or $10 \mathrm{wt} \%$ silica nanoparticles (NRS) alone in the matrix has same effects in improving fatigue strength by two to three times, compared to the fatigue strength of the neat epoxy composite, hybrid modified matrix (NRRS), i.e. the inclusion of both $\mathrm{CTBN}$ rubber and silica particles in the matrix aims to improve the fatigue strength by approximately 3 to 8 times compared to the neat composite matrix (NR) [33].

Shafi Ullah Khan et.al [34] reported that an increase of fatigue life with the inclusion of nano clay into carbon fiber reinforced composite and a peak improvement of approximately $74 \%$ with a clay content of $3 \mathrm{wt} \%$. Incorporation of $1 \%$ of carbon nanotube (CNT) in glass fiber reinforced composite leads to improve the high cycle fatigue life by 60-250\%, based on the loading situation [35]. Fenner and Daniel [36] noticed an improvement in fatigue strength and falling off in fatigue crack growth due to the incorporation of a carbon nanotube while developing the carbon fiber reinforced polymer composite. 
This strength gain may be due to the enhancement in energy inclusion from the fracture of nanotubes bridging across nanoscale cracks and nanotube pull-out from the matrix.

Several researchers have worked on improving the fatigue life of FRP composite material by inclusion of filler material to a matrix; some of them are described in Table 2.

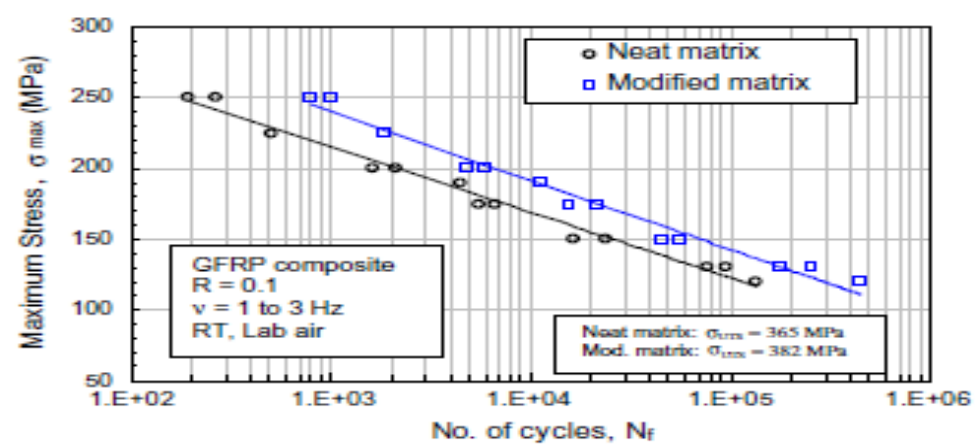

Figure 7: S-N Curve with Neat and Modified Epoxy Matrix (10 wt \% Silica Nano Particle) for GFRP Composite.

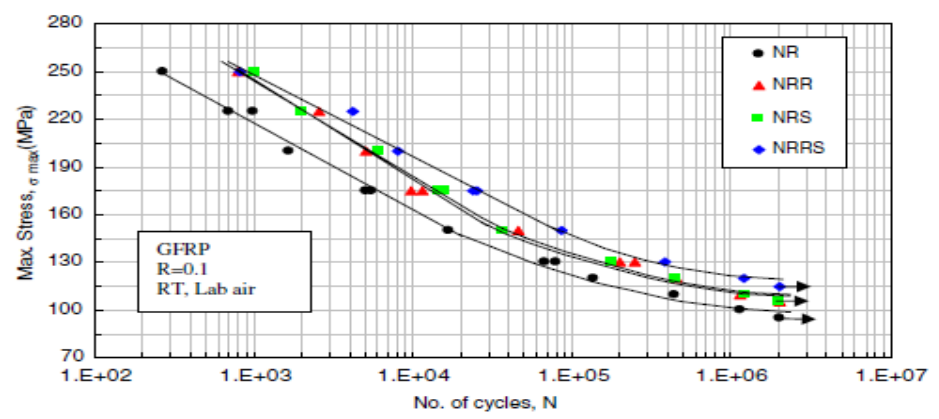

Figure 8: S-N Curves of the GFRP Composite.

Table.2: Filler Material Effect on Fatigue Behavior

\begin{tabular}{|c|c|c|c|c|c|c|}
\hline & Fiber & Matrix & Filler Material & $\mathbf{R}$ & $\mathbf{f}(\mathrm{Hz})$ & Observations \\
\hline Goriparthi [38] & -- & $\begin{array}{l}\text { Polyoxy } \\
\text { methylene }\end{array}$ & $\begin{array}{l}\text { Carbon nanotubes } \\
(0.25 \text { to } 2 \%)\end{array}$ & 0.3 & 5 & $\begin{array}{l}\text { Maximum improvement of fatigue life } \\
\text { was observed by adding } 1 \mathrm{wt} \% \text { of CNT's }\end{array}$ \\
\hline Carvelli [39] & Carbon & epoxy & $\begin{array}{l}\text { Micro fibrrillated } \\
\text { Cellulose }(0.3 \% \text { of } \\
\text { the resin weight })\end{array}$ & 0.1 & 5 & $\begin{array}{l}\text { Takes same number of cycles to failure } \\
\text { when load increases from } 85 \% \text { to } 95 \% \\
\text { of ultimate load }\end{array}$ \\
\hline Moustafa [40] & Glass & $\begin{array}{l}\text { Polyesterre } \\
\quad \sin \end{array}$ & $\begin{array}{l}\text { Cellulose nano } \\
\text { Crystal }(2,4,6 \% \text { wt })\end{array}$ & & & $\begin{array}{l}\text { The inclusion of } 4 \% \text { cellulose } \\
\text { nanocrystal into the polyester matrix } \\
\text { results in the optimum properties of } \\
\text { tensile and fatigue. }\end{array}$ \\
\hline Tugay [41] & Carbon & epoxy & $\begin{array}{l}\text { Carbon nanotube } \\
\text { And boron nitride } \\
\text { nanoplates }\end{array}$ & 0.05 & & $\begin{array}{l}\text { Addition of nanoscale reinforcement } \\
\text { Improves fatigue performance. }\end{array}$ \\
\hline Nazil [42] & Carbon & $\begin{array}{l}\text { Araldite } \\
\text { LY1556 }\end{array}$ & $\begin{array}{l}\text { Nanocarboxylic } \\
\text { Acrylonitrile } \\
\text { Butadiene rubber }\end{array}$ & 0.1 & & $\begin{array}{l}\text { By incorporating nanorubber enhance the } \\
\text { composite's fatigue life by factor of } 2\end{array}$ \\
\hline Knoll [43] & Carbon & Epoxy & $\begin{array}{l}\text { multi-wallcarbon } \\
\text { nanotubes and } \\
\text { Graphene }\end{array}$ & 0.1 & 6 & $\begin{array}{l}\text { The fatigue life, however, increased } \\
\text { significantly for both types of carbon } \\
\text { nanoparticles. }\end{array}$ \\
\hline Ferreira [44] & $\begin{array}{c}\text { Kevlar } \\
(\mathrm{BD})\end{array}$ & $\begin{array}{l}\text { Epoxy } \\
\text { resin }\end{array}$ & $\begin{array}{l}\text { Organoclay Cloisite } \\
\text { 30B }\end{array}$ & 0.1 & 10 & $\begin{array}{l}\text { Fatigue strength increases by } 12 \% \\
\text { compared to unfilled matrices }\end{array}$ \\
\hline Manjunatha [45] & Glass & epoxy & $\begin{array}{l}9 \text { wt\% carboxyl } \\
\text { Terminated Butadine }\end{array}$ & 0.1 & $1-3$ & $\begin{array}{l}\text { GFRP composite fatigue behavior } \\
\text { increased around } 6 \text { to } 10 \text { times as a result }\end{array}$ \\
\hline
\end{tabular}




\begin{tabular}{|l|l|l|l|l|l|l|}
\hline & & & $\begin{array}{l}10 \mathrm{wt} \% \text { acrylonitrile } \\
\text { rubber micro } \\
\text { particles }\end{array}$ & & of matrix hybridization. \\
\hline Akinyede [46] & $\begin{array}{c}\text { Glass } \\
\text { (BD) }\end{array}$ & epoxy & Alumina nanoparticle & 0.1 & 2 & $\begin{array}{l}\text { No major effect of hybridization of fiber } \\
\text { epoxy composites on the fatigue } \\
\text { behavior. }\end{array}$ \\
\hline
\end{tabular}

\section{COMPOSITE TUBES}

It is well known that since the 1950s, the need for FRP composite pipes has emerged in terms of manufacturing and also in a variety of applications, as shown in fig 9 [46-47]. FRP composite pipes attracting more users because of its good quality and long-term price advantages. In general, FRP composite pipes will show good stability at low weight ratio, good resistance to corrosion, low friction coefficient, low thermal conductivity and excellent dimensional stability and, more importantly, lower investment and repair cost [48-49]. Any strong combination of FRP tubes can be an efficient substitute for classical materials like stainless steel, carbon steel, lined steel materials [50-53].

Capela et. al. [54] examined the fatigue strength of circular composite specimens made from carbon fiber reinforcement. Fatigue performance was analyzed under various torsional and mean stress levels. Fatigue strength was drastically reduced with the increase in mean stress levels. For the lower shear stress levels failure was observed around $45^{0}$ planes whereas for higher stress levels torsional buckling was witnessed by the authors. Compressive buckling was also observed under pure bending due to cross-section failure. Pure torsional stresses caused the circular specimens to fail in a transverse direction. Kar et. al. [55] conducted T-T fatigue tests on glass/carbon hybrid composite rod. Tests were conducted at three stress ratios and for different maximum applied stress levels. The author concluded that the fatigue resistance and the damage mechanisms of the hybrid rod depend on the stress ratio and maximum applied stress level. Ellyin et.al [56] investigated the effects of holding in purified water at two temperatures on the mechanical characteristics of epoxy composite tubes reinforced by glass fiber. They carried out a multi-axial test to characterize the properties, the strength and rigidity of the tube decreased for all biaxial stress ratios and samples immersed at a higher temperature. Immersion period in seawater will influence on the fatigue life [57].

Reducing fatigue life may be due to the chemical changes in a matrix, and immersion duration, and change in the $\mathrm{PH}$ value of the seawater. Necmettin et al [58] studied fatigue behaviour of glass/epoxy $\pm 55^{\circ}$ filament-wound tubes subjected to internal pressure. Tests were conducted at different load ranges from 30 to $70 \%$ of the ultimate strength. The microcracking began along the direction of the fiber winding. Further, increasing in the number of cycles leads to the nucleation of microcracks and the formation of macro cracks along the fiber wounded direction. Fiber orientation and loading also influence on the fatigue strength [59-60-62].The tubular shape samples were developed by woven roving glass fiber reinforced polyester composites for $\left[ \pm 45^{0}\right] 2 \mathrm{~S}$ and $\left[0,90^{0}\right] 2 \mathrm{~S}$ direction. The $\left[ \pm 45^{0}\right] 2 \mathrm{~S}$ orientated composite showed higher fatigue strength than $\left[0,90^{\circ}\right] 2 \mathrm{~S}$ at all stress ratios [59]. Filament wounded pipes subjected to internal pressure are mainly failed in three-stage whitening, leakage, and final failure [60-62]. But, in high load condition leakage and final failure occurs same time. Whereas, low applied load condition, leakage is followed by final failure [60]. The fatigue characteristics of composite pipes with surface cracks in corrosive conditions under different internal pressure studied by Avci et al [61]. The fatigue crack propagation behavior depends to a large extent on the crack parameters. 


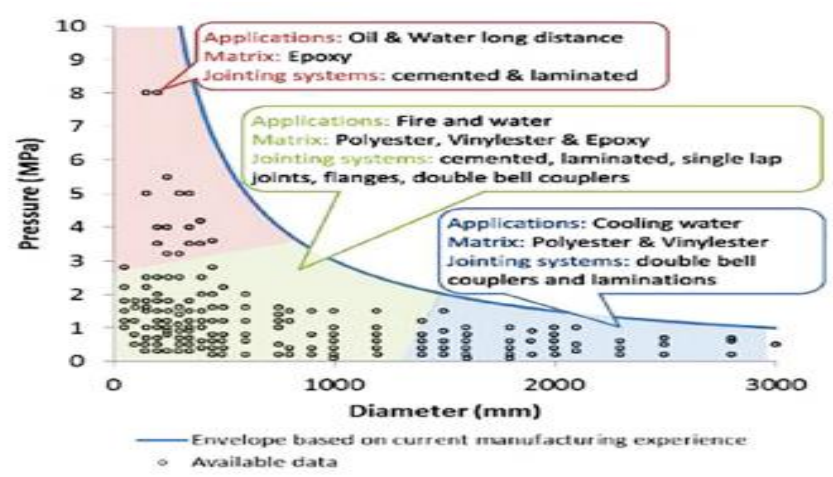

Figure 9: Application of FRP Composite Pipes.

\section{FIBER VOLUME FRACTION}

The quantitative measurement of the fibers in a composite material is the fiber volume fraction. The fiber volume fraction is expressed in the relative proportion of fiber, and the matrix is integrated into the laminate. Volume fraction influences all characteristics of a given system of materials, for example, static and fatigue behavior. In general, with higher fiber content the toughness, strength, and load capacity of the laminate is increased. The optimal value for the fraction of the fiber is $45-60 \%$. However, reaching the volume of fiber around $6070 \%$, composite strength can reach a maximum point and then begin to decrease due to the shortage of adequate resin to completely bind the fibers together. Fiber volumefraction increases the tensiontension fatigue life for all tested angles $0^{\circ}, 45^{\circ}$ and $90^{\circ}$. Observations of this study are listed in Table 3[63].

Table.3 Shows Allah et al [64]. Conducted the fatigue test at zero mean stress on polymer rods. With the help of customized pultrusion method samples are prepared with specific fiber volume fractions ( Vf $=0,0.158,0.318$ and 0.447$)$. The stiffness of the specimen decreases rapidly and during the initial fatigue test phase, It was observed that around one-fourth of its initial stiffness had been achieved. Some factors such as fiber cuttings on the surface of the sample, shear breaks on the sample waist, and surface defects in glass fibers can contribute to it. The fatigue characteristics of the glass/epoxy composite was studied by Mini et.al [65] varying fiber volume fractions ranging from $34 \%$ to $57 \%$. The author observed that as the volume fraction increases young's modulus also increases and reaches a maximum and then decreases for further increase in fiber volume fraction. Accumulation of damage within a composite matrix reduces as the proportion of the fiber-volume increases [66].

Table.3: Effect of Fiber Volume Fraction and Orientation

\begin{tabular}{|c|c|c|}
\hline Orientation & Type of Loading & Observations \\
\hline $0^{0}$ & \multirow{3}{*}{$\begin{array}{l}\text { Tension-Tension fatigue } \\
\text { loading }\end{array}$} & Fiber pullout or breakage of single fibre was observed \\
\hline $45^{0}$ & & Fatigue life improved with increase in fiber volume fraction. \\
\hline $90^{0}$ & & $\begin{array}{l}\text { For } 55 \% \text { fiber volume fraction nominal stress increase about } 40 \% \\
\text { compared to } 30 \% \mathrm{~V}_{\mathrm{f}}\end{array}$ \\
\hline
\end{tabular}

\section{SUMMARY}

Composites have played a crucial role in certain fields of use such as aerospace,aircraft, sports equipment, marine, and automotive industries. Cyclic loads are typical in these applications and major, structural fatigue will induce this type of condition of loading. Many of the advantages of polymer composite materials over traditional materials are superior strength, high stiffness, corrosion resistance, better fatigue performance.

In this review, an attempt was made to compile and comprehend the disseminated literature by focusing on the importance of knowing the fatigue performance of fiber-reinforced polymers with varying environmental conditions and 
nano-filler interactions. Some factors studied related to fatigue behavior in different environment conditions such as moisture and change in temperature.

The strength of FRPs is of concern because exposure to fatigue loading can harm and degrade the fiber/matrix or fiber/matrix interface or whole composite properties. Therefore, the progress of fiber-reinforced polymer composites is the opertunity to develop an innovative low weightage of durable structural materials.

FRP composites are viscoelastic in behavior, temperature-sensitive and also the property of the polymer is strongly affected by the glass transition temperature. The polymer converts a solid glassy material into a soft rubbery material at this temperature, there by losing some of its stiffness. Temperature also affects the fatigue life of FRP composites. By review, it is concluded that the composite fails earlier at higher temperatures. However, the composite materials fatigue strength and fatigue life increase at cryogenic or lower temperatures.

The evaluation of filler material as reinforcement in fiber-reinforced polymers certainly contributed benefits to the composite globe, addition of filler material exhibit extraordinarily good strength and rigidity, wide specific surface area and resistance to fatigue. The positive existence of all of these properties makes it robust and strong in the FRP composites.

As discussed in the earlier section, several investigations were carried out from various points of view to characterize the mechanical performance of GFRP tubes. There are still some essential and complex aspects that need to be strengthened and the fatigue behavior of hybrid polymer composites addressed.

Fibers are the primary carrier of load in composite structures, and their properties are influenced by the quantity of fiber in a composite. The fibre content increases the composite material's stiffness against the bending load. From some paper it is found that young's modulus increases as the volume fraction increases and it reaches a peak position and then the decrease in young's modulus was observed with further increases in the volume fraction.

\section{REFERENCES}

1. Peter Davies, Gregory Germain, Benoit Gaurier, Amelie Boisseau and Dominique Perreux., "Evaluation of the durability of composite tidal turbine blades". Phil Trans R Soc A 371: 20120187.2013.

2. Shenoi RA, Wellicome, JF. "Composites in maritime structures". Cambridge, UK: Cambridge University Press. 2008.

3. Martin R. Ageing of composites. Cambridge, UK: Woodhead Publishing. 2008.

4. Maurin R, Perrot Y, Bourmaud A, Davies P, Baley C. "Seawater ageing of low styrene emission resins for marine composites: mechanical behaviour and nano-indentation studies". Composites A 40, 1024-1032. 2009.

5. Mallick PK. Fiber reinforced composites: materials, manufacturing and design. 3rd ed. Florida: CRC Press, 2008.

6. Хи HHK, Ostertag CP, Braun LM, et al. "Effects of fiber volume fraction on mechanical properties of SiC-fiber/Si3N4 matrix composites". J Am Ceram Soc 1994; 77: 1897-1900.

7. Gojny FH, Wichmann MHG, Kopke U, et al. "Carbon nanotube reinforced epoxy composites: enhanced stiffness and fracture toughness at low nanotube content". Compos Science Techno 2004; 64: 2363-2371.

8. Omar, ADELA., M. El-Shennawy, and M. Ayad. "Study of Wear Behavior of as Cast TiC/7075 Composite." International Journal of Mechanical Engineering 4.4 (2015): 4552.

9. Miyagawa H and Drzal LT. "Thermo-physical and impact properties of epoxy nanocomposites reinforced by singlewall carbon nanotubes". Polymer; 45: 5163-5170. 2004. 
10. Zhou Y, Pervin F, Jeelani S, et al. "Improvements in mechanical properties of carbon fabric-epoxy composite using carbon nanofibers". J Mater Process Technol; 198: 445-453.2008.

11. Iwahori Y, Ishiwata S, Sumizawa T, et al. Mechanical properties improvements in two-phase and three phase composites using carbon nano-fiber dispersed resin. Compos Part A Appl Sci Manuf; 36: 1430-1439. 2005.

12. Habeeb, Majeed A. "Effect of Nanosilver Particles on Thermal and Dielectric Properties of (PVA-PVP) Films." International Journal of Applied and Natural Sciences 2.4 (2013): 103108.

13. Altin KM, Gökkaya $H$. "A review on machinability of carbon fibre reinforced polymer (CFRP) and glass fibre reinforced polymer (GFRP) composite materials". Def Technol 2018;14:318-26. https://doi.org/10.1016/J.DT.2018.02.001.

14. Kumre A, Rana RS, Purohit R. "A Review on mechanical property of sisal glass fibre reinforced polymer composites". Mater Today Proc 2017;4:3466-76. https://doi. org/10.1016/J.MATPR.2017.02.236.

15. Reddy, T. BALARAMI. "Mechanical performance of green coconut fiber/HDPE composites by using flexural strength." International Journal of Mechanical Engineering (IJME), 3 (1), 5366 (2014).

16. Yang DK,KorosWJ,Hopfenberg HB, Stanneyy VT: "The effect of morphology and hygrothermal aging on water absorption and transport in Kapton polyimide". J Appl poly sci 31:1619-1629. Doi:10.1002/app.1986.070310608.1986.

17. Han M-H, Nairn J A, "Hygrothermal aging of polyimide matrix composite laminates". Compos part Appl Sci Manuf 34:979-986 Doi:10.1016/S1359-835X (03)00154-4. (2003).

18. Abdelhaleem, A. M., Megahed, M., \& Saber, D. (2018). "Fatigue behavior of pure polypropylene and recycled polypropylene reinforced with short glass fiber". Journal of Composite Materials, 52(12), 1633-1640.

19. Ismail, Mahmud Rasheed, Z. A. A. A. Ali, and Muhannad Al-Waily. "Delamination damage effect on buckling behavior of woven reinforcement composite materials plate." International Journal of Mechanical \& Mechatronics Engineering IJMME-IJENS 18.05 (2018): 8393.

20. E.poodts, G.Minak, A.Zucchelli. "Impact of Sea-Water on the quasi static and fatigue flexural properties of GFRP". Journal of Composite Structures, 222-230. (2013).

21. MA Abd EI-Baky, MA Attia, "Flexural fatigue performance of hybrid composite laminates based on E-glass and polypropylene fibers". Journal of Thermoplastic Composite Materials.2018.

22. R. F. Dickson, C. J. Jones, B. Harris, D. C. Leach, D. R. Moore. "The environmental fatigue behavior of carbon fibre reinforced polyether ether ketone". Journal of Materials Science. January 1985, Volume 20, Issue 1, pp 60-70.

23. N.Tual, Carrerea, P.Davies, T.Bonnemains, E.Lolivec. "Characterization of sea water ageing effects on mechanical properties of carbon/epoxy composites for tidal turbine blades". Composites Part A: Applied Science and Manufacturing, Volume 78, November 2015, Pages 380389.

24. Y. Menail, A. El Mahi El Mahi, M. Assarar, B. Redjel, A. Kondratas. "The effects of water aging on the mechanical properties of glass-fiber and kevlar-fiber epoxy composite materials". ISSN 1392 - 1207. MECHANIKA. 2009. Nr.2(76).

25. Ahlborn K."Fatigue behaviour of carbon fiber reinforced plastic at cryogenic temperatures". Cryogenics 1988; 28:267-272.

26. J.Vina, A.Arguelles, A.F.Canteli. "Influence of Temperature on the Fatigue Behavior of Glass Fiber Reinforced Polypropylene". Blackwell Publishing Ltd. 2011: 47,222-226.

27. Jen M-HR, Testing Y-C, Kung H-K, Huang J C "Fatigue response of APC-2 composite laminates at elevated temperatures". Compos part B Eng 39:1142-1146.2008, Doi:10.1016/j.compositesb.2008.03.005. 
28. Charalambous $G$, Allegri $G$, Hallett SR "Temperature effects on mixed mode I/II delamination under quasi static and fatigue loading of a carbon/epoxy composite". Compos Part Appl sci Manuf 77:75-86,2015, Doi:10.1016/j/compositesa.2015.05.016.

29. P.Coronadoa, A. Arguellesa, J.Vina, V Mollsnb, I.Vina. "Influence of temperature on a carbon-fibre epoxy composite subjected to static and fatigue loading under mode-I delamination". International Journal of Solids and Structures.2012, Pages 29342940 .

30. Hussain Al-alkawi J, Dhafir Al-Fattal S and Abdul-Jabar Ali H. "Fatigue behavior of woven glass fiber reinforced polyester under variable temperature". Elixir mech Eng 2012; 53: 12045-12050.

31. Jamison RD, Schulte K, Reifsnider KL, Stinchcomb WW "Characterization and analysis of damage mechanisms in tension tension fatigue of graphitelepoxy laminates". ASTM publications, Philadelphia,pp 21-25.1984.

32. Baron $C$, Schulte $K$, Haring $H$ "Influence of fiber and matrix failure strain on static and fatigue properties of carbon fiber reinforced plastics. Compo sci technol 29: 257-272.1987,doi:10.1016/0266-3538(87)90075-3.

33. Andrews R, Weisenberger MC"carbon nano tube polymer composites". Curropin solid state mater sci 8:31-37.2004, Doi:101016/j.cossms.2003.10.006.

34. Xie X-L, Mai $Y$-W, Zhou X-P "Dispersion and alignment of carbon nanotubes in polymer matrix: a review". Mater sci Eng $R$ Rep 49:89-112.2005,doi:10.1016/j.mser.2005.04.002.

35. Koerner H, Price G, Pearce NA et al "Remotely actuated polymer nanocomposites-stress-recovery of carbon nanotube-filled thermoplastic elastomers". Nat Mater 3:115:120.2004, doi10.1038/nmat1059.

36. C.M.Manjunatha, A.C.Taylora, A.J.Kinlocha, S. Sprenger. The tensile fatigue behaviour of a silica nanoparticle-modified glass fibre reinforced epoxy composite. 2010, Pages 193199.

37. Manjunatha, C. M., Taylor, A. C., Kinloch, A. J., \& Sprenger, S. 'The effect of rubber micro-particles and silica nano-particles on the tensile fatigue behaviour of a glass-fibre epoxy composite". Journal of Materials Science, 44(1), 342-345.2008.

38. ShafiUllahKhan,Arshad Munir, RizwanHussain, Jang-KyoKim. "Fatigue damage behaviors of carbon fiber-reinforced epoxy composites containing nanoclay". Composites Science and TechnologyVolume 70, Issue 14, 30 November 2010, Pages 2077-2085.

39. Christopher S. Grimmer, C. K. H. Dharan. High-cycle fatigue of hybrid carbon nanotube/glass fiber/polymer composites. Journal of Materials Science, 2008, Volume 43, Number 13, Page 4487.

40. Joes S. Fenner, Isaac M. Daniel., Hybrid nano reinforced carbon/epoxy composites for enhanced damage tolerance and fatigue life. Elsevier science: 2014.

41. Bhanu $k$ goriparthi, PNE Naveen, H ravishankar, Somanath Ghosh, Effect of functionalization and construction of carbonnanotubes on mechanical wear and fatigue behavior of polyoxymethylene/carbon nanotube nanocomposite.Bull Mater sci42, 98(2019).

42. Valter Carvelli, Toru Fujii, Kazuya Okuba. The effect of microfibrils cellulose modified epoxy on the quasi-static and fatigue behavior of open hole carbon texile composite. Journal of composite material.Volume: 52 issues: 24, page (s): 3365-3380,2018.

43. Zaghloul, M. M. Y., Mohamed, Y. S., \& El-Gamal, H. (2018). Fatigue and tensile behaviors of fiber-reinforced thermosetting composites embedded with nanoparticles. Journal of Composite Materials, Volume: 53 issue: 6, page(s): 709-718.

44. Ustun, T., Eskizeybek, V., \& Avci, A. (2016). Enhanced fatigue performances of hybrid nanoreinforced filament wound carbon/epoxy composite pipes. Composite Structures, 150,124-131.

45. Ozdemir, N. G., Zhang, T., Hadavinia, H., Aspin, I., \& Scarpa, F. "Influence of nanorubber toughening on the tensile deformation 
and tensile fatigue behaviour of a carbon fibre-reinforced epoxy composite". Journal of Composite Materials, 50(19), 26332645.2015

46. Knoll JB, Riecken BT, Kossmann N, et al. "The effect of carbon nanoparticles on the fatigue performance of carbon fiber reinforced epoxy". Compos Part A Appl SciManuf 2014; 67:233-240.

47. Ferreira, J., Reis, P., Costa, J., \& Richardson, M. (2012). Fatigue behaviour of Kevlar composites with nanoclay-filled epoxy resin. Journal of Composite Materials, 47(15), 1885-1895. doi:10.1177/0021998312452024.

48. Manjunatha, C. M., Sprenger, S., Taylor, A. C., \& Kinloch, A. J. (2010). The Tensile Fatigue Behavior of a Glass-fiber Reinforced Plastic Composite Using a Hybrid-toughened Epoxy Matrix. Journal of Composite Materials, 44(17), $2095-2109$. doi:10.1177/0021998309360943.

49. Akinyede, O., Mohan, R., Kelkar, A., \& Sankar, J. "Static and Fatigue Behavior of Epoxy/Fiberglass Composites Hybridized with Alumina Nanoparticles". Journal of Composite Materials, 43(7), 769-781.2009, doi:10.1177/0021998309101294.

50. Paulin FRP Pipe. failures and lessons to be. learned 2008:1-40.

51. Patrick Laney. Use of Composite Pipe Materials in the Transportation of Natural Gas. 1990;vol:64.

52. Brent Strong A. Fundamentals of composites manufacturing. Materials, methods, and applications. 2nd ed. Society of Manufacturing Engineers; 2008.

53. ISO. 14692-1. Petroleum and natural gas industries - Glass-reinforced plastics (GRP) piping - Part 1: Vocabulary, symbols, applications and. materials 2017:67.

54. Ellul B, Camilleri D, Grech J, Muscat M. Filament wound composite pressure vessels and pipes subject to an internal pressure - an Experimental and Material Characterization Study. J Press Vessel Technol 2016;138(8):60901-6. https://doi. org/10.1115/1.4032506.

55. Alderson KL, Evans KE. Dynamic analysis of filament wound pipes undergoing low velocity transverse impact. Compos Sci Technol 1992;45:17-22. https://doi.org/ 10.1016/0266-3538(92)90118-M.

56. Sebaey TA. "Design of Oil and Gas Composite Pipes for Energy Production". Energy Procedia 2019;162:146-55. https://doi.org/10.1016/j.egypro.2019.04.016.

57. Pandian A, Hameed Sultan MT, Uthayakumar M, Md Shah A. "Low Velocity Impact Studies on Fibre-Reinforced Polymer Composites and Their Hybrids - Review", 2019. doi:10.1016/B978-0-12-803581-8.11289-5.

58. C. Capela J.A.M. Ferreira, T.Febra, J.D. Costa. “Fatigue strength of tubular carbon fiber composites under bending/torsion loading”. International Journal of Fatigue. Elsevier Science:2014.

59. N.K. Kar, Y.Hu, E. Barjasteh. S.R Nutt. "Tension - tension fatigue of hybrid composite rods" Composites: Part B 43.21152124.2012.

60. Ellyin F, Maser R, "Environmental effects on the mechanical properties of glass- fiber epoxy composite tubular specimens". Compos sci Technology; 34:1863-1874:2014.

61. M. E. Deniz, M. Ozen, Okan Ozdemir, Ramazan Karakuzu, B. M. Icten. “Environmental effect on fatigue life of glass-epoxy composite pipes subjected to impact loading”. International Journal of Composites. Elsevier Science:2012.

62. Necmettin T, Lokman Gemi, Ahmet Yapici. “ Fatigue failure behavior of glass/epoxy $\pm 55^{0}$ filament wound pipes under imternal pressure". Journal of composites Sciences and Technology.Elsevier Science: 2005.

63. Mohamed Nasr NA, Abouelwafa MN, Gomaa A, et al. The effect of mean stress on the fatigue behavior of woven-roving 
glassfiber-reinforced polyester subjected to torsional moments. J Eng Mater Techno 2005; 127: 301-309.

64. L. Gemi, N. Tarakcioglu, A. Akdemir, O.S. Sahin, "Progressive fatigue failure behavior of glass/epoxy $( \pm 75)_{(2)}$ filament-wound pipes under pure internal pressure". Mater. Des. 30(10), 4293-4298 (2009).

A. Avci, O.S. Sahin, N. Tarakcioglu, "Fatigue behavior of surface cracked filament wound pipes with high tangential strength in corrosive environment. Composite". Part A Appl. Sci. Manuf. 38(4),1192-1199 2007. https://doi.org/10.1016/j.compositesa.2006.04.011.

65. Tarakcioglu N, Gemi L, Yapici A. "Fatigue failure behavior of glass/epoxy \pm 55 filament wound pipes under internal pressure". Compos Sci Technol 2005;65(3):703-8.

66. Brunbauer $J$ and Pinter G. "Effects of mean stress andfiber volume content on the fatigue-induced damage mechanisms in CFRP". Int J Fatigue 2015; 75: 28-38.

67. Abd Allah MH, Abdin EM, Selmy AI, et al. "Effect of fiber volume fraction on the fatigue behaviour of grp pultruded rod composites". Compos Sci Technol 1996; 56: 23-29.

68. Mini KM, Lakshmanan M, Mathew L, et al. "Effect of fiber volume fraction on fatigue behaviour of the glass fiber reinforced composite". Fatigue Fract Eng Mater Struct 2012; 35: 1160-1160.

69. Hiremath $C$, Senthilnathan $K$, Guha A, Tewari A. "Effect of volume fraction on damage accumulation for a lattice arrangement of fibers in CFRP". Materials Today Off: Proceedings 2015;2:2671-8. 

